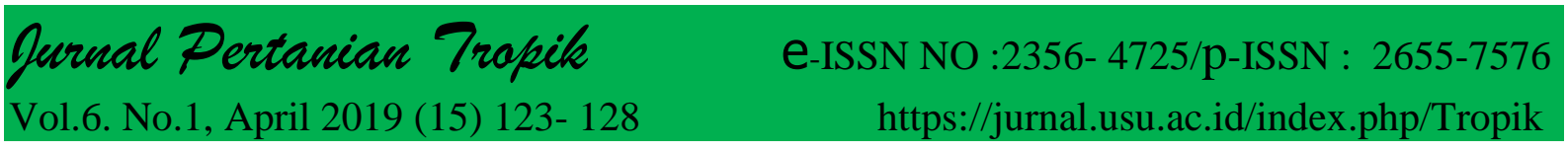

\title{
Pengamatan Parameter Genetik Kedelai [Glycine $\max$ (L.) Merril] Generasi M4 Pada Kondisi Optimum dan Cekaman Kekeringan
}

Genetic Parameter Observation at $M_{4}$ Generation of Soybean [Glycine max (L.) Merril] on optimum and drought condition

\section{Gredo Oktavianus, Diana Sofia Hanafiah*, Eva Sartini Bayu}

Program Studi Agroteknologi, Fakultas Pertanian USU, Medan 20155

*Coressponding author : dedek.hanafiah@yahoo.co.id

\begin{abstract}
The capability adaptation of soybean plant [Glycine max (L.) Merr.] at M4 generation to drought stress influence of production. This research was conducted in greenhouse and research field of Faculty of Agriculture, University of North Sumatera Utara, Medan from September 2017 until December 2017. This study used three plant populations : control plant population (Anjasmoro), population 100 Gray and population 200 Gray in generation $M_{4}$. Data analysis with t test using minitab 16 application. The genetic parameters observed were genetic variance, phenotipe variance and heritability. The results showed that there were selected population of soybean plant [Glycine max (L.) Merr.] as the result of gamma ray irradiation of $M_{4}$ generation which had good growth in drought stress condition with criteria number of productive pod, seed number per plant and the seed's weight per plant were have high score found in plant population 200 Gray. High heritability estimates are found in the number of pods per plant and the weight of seed per plant from population 100 and $200 \mathrm{~Gy}$ can be used as a selection character for drought stress conditions.
\end{abstract}

Keywords: soybean, $M_{4}$ generation, drought stress

\begin{abstract}
ABSTRAK
Kemampuan adaptasi tanaman kedelai [Glycine $\max$ (L.) Merr.] generasi $\mathrm{M}_{4}$ terhadap cekaman kekeringan akan mempengaruhi peningkatan produksi. Penelitian ini dilaksanakan di rumah kaca dan lahan penelitian Fakultas Pertanian, Universitas Sumatera Utara, Medan mulai dari bulan September 2017 sampai dengan Desember 2017. Penelitian ini menggunakan tiga populasi tanaman yaitu populasi tanaman kontrol (Anjasmoro), populasi 100 Gray serta populasi 200 Gray pada generasi M4. Analisa data secara statistik karakter tanaman populasi generasi $\mathrm{M}_{4}$ dengan tanaman populasi kontrol (Anjasmoro) dengan uji $\mathrm{t}$ menggunakan aplikasi minitab 16. Paramater genetik yang diamati adalah ragam genotipe, ragam fenotipe dan heritabilitas. Hasil penelitian menunjukkan bahwa ada populasi terpilih dari tanaman kedelai [Glycine max (L.) Merr.] hasil iradiasi sinar gamma generasi $\mathrm{M}_{4}$ yang memiliki pertumbuhan yang baik dalam kondisi cekaman kekeringan dengan kriteria jumlah polong berisi, jumlah biji per tanaman dan bobot biji per tanaman yang tinggi terdapat pada tanaman populasi 200 Gray. Nilai duga heritabilitas yang tinggi terdapat pada karakter jumlah polong per tanaman serta bobot biji per tanamana dari populasi 100 dan 200 Gy dapat dijadikan karakter seleksi untuk kondisi cekaman kekeringan.
\end{abstract}

Kata Kunci: kedelai, generasi $\mathrm{M}_{4}$, cekaman kekeringan 


\section{PENDAHULUAN}

Produktivitas tanaman kedelai ratarata di Indonesia pada tahun 2015 adalah sekitar 15,57 kuintal/Ha. Hasil ini belum mampu untuk memenuhi kebutuhan kedelai nasional yang mencapai 2,3 juta ton/tahun. Tersedianya berbagai varietas unggul kedelai diharapkan para petani kembali bergairah untuk menanam palawija, khususnya kedelai untuk memenuhi kebutuhan nasional yang saat ini masih jauh lebih besar dibandingkan dengan kemampuan produksinya. Perbaikan sifat genetik dan agronomik tanaman dapat dilakukan melalui pemuliaan. Salah satu teknik pemuliaan adalah dengan teknik mutasi radiasi (Mangoendidjojo, 2003).

Tujuan mutasi adalah untuk memperbesar variasi suatu tanaman yang dimutasi sehingga dapat dipilih sifat atau karakter tanaman yang dikehendaki. Hal itu ditunjukkan misalnya oleh variasi kandungan gizi atau morfologi dan penampilan tanaman. Semakin besar variasi, seorang pemulia atau orang yang bekerja untuk merakit kultivar unggul, semakin besar peluang untuk memilih tanaman yang dikehendaki. Melalui teknik penyinaran (radiasi) dapat menghasilkan mutan atau tanaman yang mengalami mutasi dengan sifat-sifat yang diharapkan setelah melalui serangkaian pengujian, seleksi dan sertifikasi. Penggunaan teknik penyinaran (iradiasi) sinar gamma akan mempengaruhi sifat morfologi tanaman kedelai, dengan harapan memperoleh karakter umur tanaman kedelai varietas Anjasmoro yang genjah serta produksi tinggi (Tah, 2006).

Hal ini dapat diakibatkan oleh lahan yang tidak sesuai dengan syarat tumbuh dan produktivitas varietas kedelai dan sumber unsur hara yang kurang memadai sehingga diperlukan pengoptimalam lahan. Lahan kering merupakan salah satu agroekosistem yang mempunyai potensi besar untuk usaha pertanian tanaman pangan. Permasalahan dalam pemanfaatan lahan kering untuk pertanaman tanaman pangan bervariasi baik aspek teknis maupun sosial ekonomi. Untuk meningkatkan produksi kedelai di lahan kering dapat dilakukan dengan menanam varietas unggul berdaya hasil tinggi baik secara kuantitas maupun kualitas serta mampu beradaptasi terhadap kondisi lingkungan atau agroekosistem setempat (Andrianto, 2004).

Kekurangan air selama fase pembungaan berakibat pada berkurangnya jumlah polong, jumlah biji per polong dan ukuran biji. Cekaman kekeringan menghambat distribusi karbohidrat dari daun ke polong sehingga jumlah dan ukuran biji menurun. Cekaman kekeringan selama fase R3, R5 dan R6 menurunkan hasil masing-masing 33\%, 31\% dan 50\%. Resiko penurunan hasil tersebut dapat dikurangi melalui pendekatan manipulasi lingkungan dan menanam varietas toleran kekeringan (Hartati, 2000).

Perakitan varietas baru memerlukan populasi dasar yang memiliki keragaman genetik yang tinggi yang dapat diperoleh melalui introduksi, persilangan, mutasi dan transformasi genetik. Peningkatan keragaman genetik tanaman kedelai akan mempermudah usaha seleksi untuk mendapatkan tanaman dengan sifat yang diinginkan misalnya karakter tanaman untuk ketahanan terhadap cekaman kekeringan (Hanafiah, 2010).

Heritabilitas merupakan suatu parameter yang digunakan untuk mengukur kemampuan suatu genotipe populasi tanaman dalam mewariskan karakteristik yang dimiliki. Pendugaan nilai heritabititas suatu karakter sangat terkait dengan faktor lingkungannya. Faktor genetik tidak akan mengekspresikan karakter yang diwariskan apabila faktor lingkungan tidak mendukung. Sebaliknya, sebesar apapun manipulasi yang dilakukan terhadap faktor lingkungan tidak akan mampu mewariskan 
suatu karakter yang diinginkan apabila gen pengendali karakter tersebut tidak ada (Mursito, 2003).

Heritabilitas terbagi menjadi dua yaitu heritabilitas arti luas dan heritabilitas arti sempit. Heritabilitas arti luas merupakan perbandingan antara ragam genetik total terhadap ragam fenotipe. Ragam genetik terdiri atas ragam aditif, dominan, dan epistasis. Heritabilitas arti sempit merupakan perbandingan antara ragam aditif dengan ragam fenotipe. Oleh karena itu heritabilitas dalam arti sempit mempunyai nilai yang lebih kecil dari heritabilitas dalam arti luas (Suprapto dan Khairudin, 2007).

Pada kondisi seperti itu, perbaikan karakter melalui kegiatan pemulia tidak akan memberikan harapan kemajuan secara genetik. Berikut ini adalah kriteria nilai heritabilitas menurut Nasir (1999) : Heritabilitas tinggi apabila $\mathrm{H} \geq 50 \%$ atau $\geq$ 0,5 , Heritabilitas sedang apabila $20 \%<\mathrm{H}$ $<50 \%$ atau $0,2<\mathrm{H}<0,5$, Heritabilitas rendah apabila $\mathrm{H} \leq 20 \%$ atau $\leq 0,2$.

Adapun tujuan penelitian ini adalah untuk mengetahui adaptasi tanaman kedelai [Glycine $\max ($ L.) Merr.] generasi $\mathrm{M}_{4}$ terhadap cekaman kekeringan.

\section{BAHAN DAN METODE}

Penelitian ini dilaksanakan di rumah kaca dan lahan Pertanian, Fakultas Pertanian Universitas Sumatera Utara, Medan, dengan ketinggian tempat \pm 25 meter di atas permukaan laut, yang dilaksanakan dari bulan September 2017 sampai dengan Desember 2017.

Bahan yang digunakan dalam penelitian ini adalah benih kedelai Anjasmoro, benih kedelai Anjasmoro hasil radiasi sinar gamma yaitu benih $\mathrm{M}_{4}$ dengan berbagai taraf sebagai objek yang diamati, kapur dolomite sebagai bahan tambahan untuk menggemburkan dan menetralkan $\mathrm{pH}$ tanah, pupuk kandang sebagai tambahan bahan organik, pupuk anorganik (Urea, $\mathrm{KCl}$, TSP), insektisida untuk mengendalikan hama, fungisida untuk mengendalikan jamur, dan bahan bahan lainnya yang mendukung penelitian ini.

Alat yang digunakan adalah polibag, cangkul, parang, pacak sampel, handsprayer, timbangan analitik, gembor, meteran untuk mengukur luas lahan dan tinggi tanaman, tali plastik, alat tulis, dan kalkulator.

Benih kedelai yang ditanam adalah benih generasi $\mathrm{M}_{4}$ yang diperoleh dari penelitian sebelumnya. Benih $\mathrm{M}_{4}$ di tanam dalam polibag $10 \mathrm{~kg}$ di atas 3 plot. Jarak antar plot yaitu $50 \mathrm{~cm}$. Jumlah tanaman seluruhnya yaitu 240 tanaman. Jumlah tanaman sampel yaitu 240 tanaman.

Untuk membandingkan secara statistik karakter genotipe tanaman $\mathrm{M}_{4}$ dengan tanaman populasi kontrol, maka dilakukan uji t pada taraf 5\% dan $1 \%$ dengan menggunakan software Minitab 16.

$$
\begin{gathered}
\text { T.hit }=\frac{\left|\bar{X}_{1}-\bar{X}_{2}\right|}{\mathrm{S}_{\bar{x} 1}-\bar{x} 2} \\
\mathrm{~S}_{x_{1}-\bar{x}_{2}}^{-}=\sqrt{\frac{S_{1}^{2}}{n_{1}}+\frac{S_{2}^{2}}{n_{2}}} \\
S^{2}=\frac{\left(\sum x^{2}\right)-\left[\left(\sum x\right)^{2} / n\right]}{n-1}
\end{gathered}
$$

Ket: $\quad$ T.hit $=$ nilai $t$ hitung

$\overline{\mathrm{X}}_{1}=$ nilai rataan perlakuan $\mathrm{A}$ (kontrol/ tanpa iradiasi)

$\overline{\mathrm{X}}_{2}=$ nilai rataan perlakuan $\mathrm{B}$ (masing-masing perlakuan yang diberi iradiasi)

$\mathrm{S} \overline{\mathrm{X}}_{1}-\overline{\mathrm{X}}_{2}=$ galat baku dari selisih nilai rataan $x x$

$\mathrm{S}^{2}=$ nilai ragam

$n=$ jumlah anggota populasi (Sastrosupadi, 2000).

\section{Heritabilitas}

$$
\mathrm{H} \text { atau } \mathrm{h}^{2}=\frac{\sigma^{2} G}{\sigma^{2} P}
$$


$\sigma^{2} \mathrm{G}=$ Varians Genotipe

$\sigma^{2} \mathrm{~F}=$ Varians Fenotipe

Kriteria heritabilitas adalah sebagai

berikut:

$\mathrm{h}^{2}>0,5 \quad$ : tinggi

$\mathrm{h}^{2} 0,2-0,5 \quad$ : sedang

$\mathrm{h}^{2}<0,2 \quad$ : rendah (Stansfield, 1991).

\section{HASIL DAN PEMBAHASAN}

\section{Heritabilitas}

Data heritabilitas tanaman hasil iradiasi sinar gamma pada generasi $\mathrm{M}_{4}$ populasi $100 \mathrm{~Gy}$ di areal tanam lahan dan rumah kaca dapat dilihat pada Tabel 1 .

Nilai heritabilitas dengan kisaran nilai sedang tanaman Generasi $\mathbf{M}_{4}$ pada populasi 100 Gy terdapat pada parameter jumlah polong hampa per tanaman di lahan serta parameter tinggi tanaman, jumlah cabang primer serta jumlah polong hampa per tanaman di rumah kaca. Nilai heritabilitas dengan kisaran nilai tinggi tanaman Generasi $\mathbf{M}_{4}$ pada populasi 100 Gy terdapat pada parameter jumlah polong per tanaman di rumah kaca.

Data heritabilitas tanaman hasil iradiasi sinar gamma pada generasi $\mathrm{M}_{4}$ dengan dosis 200 Gy pada areal tanam lahan dan rumah kaca dapat dilihat pada Tabel 2.

Nilai heritabilitas dengan kisaran nilai sedang tanaman Generasi $\mathrm{M}_{4}$ pada populasi 200 Gy terdapat pada parameter umur panen, jumlah polong per tanaman dan bobot biji pertanaman di lahan serta parameter umur berbunga, tinggi tanaman dan jumlah biji per tanaman di rumah kaca. Nilai heritabilitas dengan kisaran nilai tinggi tanaman Generasi $\mathrm{M}_{4}$ pada populasi 200 Gy terdapat pada parameter jumlah polong hampa per tanaman di lahan serta parameter jumlah polong per tanaman, jumlah polong hampa per tanaman dan bobot biji per tanaman di rumah kaca.

Berdasarkan Tabel 1 dan 2 dapat dilihat bahwa rataan nilai heritabilitas pada populasi 100 Gy di rumah kaca lebih tinggi daripada di lahan untuk seluruh parameter pengamatan dan pada populasi 200 Gy di parameter umur panen rataan nilai heritabilitas di lahan lebih tinggi daripada di rumah kaca sedangkan parameter lainnya rataan nilai heritabilitas di rumah kaca lebih tinggi daripada di lahan. Heritabilitas tinggi menunjukkan bahwa variabilitas genetik besar dan variabilitas lingkungan kecil. Nilai heritabilitas yang tinggi disebabkan oleh lingkungan yang relatif homogen, hal ini berarti penampilan suatu karakter lebih dipengaruhi oleh faktor genetik daripada faktor lingkungan. Hal ini berarti genotipe yang digunakan dalam penelitian ini memiliki peluang besar untuk mewariskan sifat sifat tersebut pada keturunannya.

Seleksi terhadap karakter yang memiliki heritabilitas tinggi akan lebih efektif dibanding dengan pengaruh lingkungan yang berperan dalam ekspresi karakter tersebut. Hal ini sesuai dengan literatur Nasir (1999) menyatakan bahwa tingginya nilai heritabilitas dalam arti luas untuk karakter agronomi ini diduga disebabkan oleh relatif homogennya lokasi percobaan dan relatif kecilnya perbedaan antar plot percobaan baik dalam blok maupun antar blok itu sendiri. Berdasarkan Tabel 1 dan 2 diperoleh nilai heritabilitas yang beragam baik positif dan negatif. Terdapat juga nilai heritabilitas yang rendah yaitu negatif. Ini menandakan bahwa faktor lingkungan lebih besar dibandingan dengan factor genetik. Populasi tanaman dengan sifat-sifat heritabilitas tinggi memungkinkan dilakukan seleksi, sebaliknya dengan heritabilitas rendah masih harus dilihat tingkat rendahnya, yakni bila terlalu rendah (hampir mendekati nol), berarti tidak akan banyak berguna bagi pekerjaan seleksi tersebut. Menurut Makmur (1985), besaran nilai heritabilitas dapat digunakan untuk menentukan apakah seleksi yang dilakukan terhadap suatu sifat dari populasi tanaman pada lingkungan tertentu mengalami kemajuan genetik atau tidak. 
Tabel 1. Heritabilitas Pada Tanaman Hasil Iradiasi Sinar Gamma Generasi M4 Populasi 100 Gray

\begin{tabular}{|c|c|c|c|c|c|c|}
\hline \multirow{3}{*}{ Parameter } & \multicolumn{6}{|c|}{100 Gray } \\
\hline & & Rumah & & Rumah & & Rumah \\
\hline & Lahan & Kaca & Lahan & Kaca & Lahan & Kaca \\
\hline Umur Berbunga (hari) & 7,3 & 7,66 & 0,57 & 1,22 & $0,08(\mathrm{r})$ & $0,16(r)$ \\
\hline Umur Panen (hari) & 7,64 & 7,06 & 1,32 & 0,97 & $0,17(\mathrm{r})$ & $0,17(r)$ \\
\hline Tinggi Tanaman $(\mathrm{cm})$ & 43,53 & 38,89 & 2,98 & 12,49 & $0,07(\mathrm{r})$ & $0,32(s)$ \\
\hline $\begin{array}{l}\text { Jumlah Cabang Primer } \\
\text { (cabang) }\end{array}$ & 0,56 & 0,55 & 0,05 & 0,15 & $0,08(\mathrm{r})$ & $0,27(\mathrm{~s})$ \\
\hline $\begin{array}{l}\text { Jumlah Polong Per } \\
\text { Tanaman (polong) } \\
\text { Jumlah Polong Hampa Per }\end{array}$ & 52,98 & 11,45 & 3,12 & 6,69 & $0,06(r)$ & $0,58(t)$ \\
\hline Tanaman (polong) & 6,02 & 6,46 & 1,67 & 2,86 & $0,28(\mathrm{~s})$ & $0,44(s)$ \\
\hline $\begin{array}{l}\text { Jumlah Biji Per Tanaman } \\
\text { (biji) } \\
\text { Bobot Biji Per Tanaman }\end{array}$ & 330,12 & 33,56 & 17,91 & 3,62 & $0,05(\mathrm{r})$ & $0,11(r)$ \\
\hline (gr) & 5,84 & 0,64 & 0,38 & 0,2 & $0,06(\mathrm{r})$ & $0,31(\mathrm{~s})$ \\
\hline
\end{tabular}

Keterangan : Kisaran Nilai Heritabilitas Tanaman Generasi $\mathrm{M}_{4}(\mathrm{r})=$ rendah ; $(\mathrm{s})=$ sedang dan $(\mathrm{t})=$ tinggi

Tabel 2. Heritabilitas Pada Tanaman Hasil Iradiasi Sinar Gamma Generasi M4 Populasi 200 Gray

\begin{tabular}{|c|c|c|c|c|c|c|}
\hline \multirow{3}{*}{ Parameter } & \multicolumn{6}{|c|}{200 Gray } \\
\hline & \multicolumn{2}{|c|}{ Ragam Penotip } & \multicolumn{2}{|c|}{ Ragam Genotip } & \multicolumn{2}{|c|}{ Heritabilitas } \\
\hline & Lahan & $\begin{array}{l}\text { Rumah } \\
\text { Kaca }\end{array}$ & Lahan & $\begin{array}{l}\text { Rumah } \\
\text { Kaca }\end{array}$ & Lahan & $\begin{array}{l}\text { Rumah } \\
\text { Kaca }\end{array}$ \\
\hline Umur Berbunga (hari) & 8,02 & 8,74 & 1,29 & 2,3 & $0,16(\mathrm{r})$ & $0,26(s)$ \\
\hline Umur Panen (hari) & 8,29 & 7,14 & 1,98 & 1,05 & $0,24(\mathrm{~s})$ & $0,15(r)$ \\
\hline Tinggi Tanaman (cm) & 46,69 & 36,24 & 6,14 & 9,83 & $0,13(\mathrm{r})$ & $0,27(s)$ \\
\hline $\begin{array}{l}\text { Jumlah Cabang Primer } \\
\text { (cabang) }\end{array}$ & 0,6 & 0,49 & 0,09 & 0,09 & $0,15(\mathrm{r})$ & $0,18(r)$ \\
\hline $\begin{array}{l}\text { Jumlah Polong Per Tanaman } \\
\text { (polong) }\end{array}$ & 64,39 & 29,95 & 14,53 & 25,2 & $0,23(\mathrm{~s})$ & $0,84(t)$ \\
\hline Jumlah Polong Hampa Per & & & & & & \\
\hline Tanaman (polong) & 15,51 & 13,62 & 11,16 & 10,02 & $0,72(t)$ & $0,74(\mathrm{t})$ \\
\hline Jumlah Biji Per Tanaman (biji) & 316,51 & 53,95 & 4,3 & 24,02 & $0,01(\mathrm{r})$ & $0,45(\mathrm{~s})$ \\
\hline Bobot Biji Per Tanaman (gr) & 6,92 & 0,95 & 1,46 & 0,51 & $0,21(\mathrm{~s})$ & $0,53(\mathrm{t})$ \\
\hline
\end{tabular}

Keterangan : Kisaran Nilai Heritabilitas Tanaman Generasi $\mathrm{M}_{4}(\mathrm{r})=$ rendah ; $(\mathrm{s})=$ sedang dan $(\mathrm{t})=$ tinggi

\section{SIMPULAN}

Adanya populasi terpilih dari tanaman kedelai [Glycine max (L.) Merr.] hasil iradiasi sinar gamma generasi $\mathrm{M}_{4}$ yang memiliki pertumbuhan yang baik dalam kondisi cekaman kekeringan dengan kriteria jumlah polong, jumlah biji dan bobot biji yang tinggi terdapat pada tanaman populasi 200 Gray. Nilai duga heritabilitas yang tinggi pada masing-masing populasi terdapat pada karakter jumlah polong per tanaman serta bobot biji per tanamana dari populasi 100 dan 200 Gy. 


\section{DAFTAR PUSTAKA}

Andrianto, T. T. 2004. Budidaya dan Analisis Usaha Tani Kedelai. Penerbit Absolut, Yogyakarta.

Hanafiah, D. S., Trikoesoemaningtyas., S. Yahya dan D. Wirnas. 2010. Penggunaan Mikro Iradiasi Sinar Gamma untuk Meningkatkan Keragaman Genetik pada Varietas Kedelai Argomulyo (Glycine max L. Merr). Jurnal Natur Indonesia 14(1) : 8085. ISSN 14109379.

Hartati, S. 2000. Penampilan Genotip Tanaman Tomat (Lycopersicum Esculentum Mill.) Hasil Mutasi Buatan Pada Kondisi Stress Air dan Kondisi Optimal, Agrosains Volume 2 No. 2, 2000.

http://pertanian.uns.ac.id// agronomi/ag rosains/pen_genotip_tomat_srihartati.pd f. [9 Maret 2016].

Makmur, A. 1985. Pokok - Pokok Pengantar Pemuliaan Tanaman. Jurusan Budidaya Pertanian Institut Pertanian Bogor. Bogor.

Mangoendidjojo, W. 2003. Dasar - Dasar pemuliaan Tanaman. Kanisius. Jakarta
Martin, F. W., 1998. Soybean. ECHO, USA.

Mursito, J. 2003. Heritabilitas dan Sidik Lintas Karakter Fenotipik Beberapa Galur Kedelai (Glycine Max. (L.) Merrill). Fakultas Pertanian, Universitas Sebelas Maret, Surakarta. J. Agrosains 6(2): 5863, 2003.

Nasir, M. 1999. Heritabilitas dan Kemajuan Genetik Harapan Karakter Agronomi Tanaman Lombok (Capsicum annuum L.) Dalam Habitat. (109) 11.p.1-8.

Sastrosupadi, A. 2000. Rancangan Percobaan Praktis Bidang Pertanian. Kanisius.Yogyakarta.

Suprapto dan N . Md. Khairudin. 2007. Variasi Genetik, Heritabilitas, Tindak Gen Dan Kemajuan Genetik (Glycine max Merril) Pada tanah ultisol. J. Pert Indon 9 (2) : 183190.

Stansfield, W. D., 1991. Genetika . Alih Bahasa M. Affandi dan L, T. Hardy: Erlangga, Jakarta.

Tah, P.R. 2006. Studies on gamma ray induced mutations in mungbean [Vigna radiata (L.) Wilczek]. Asian Journal of Plant Science, 5(1):61-70. 